\title{
Leadership Potential of Professional Teacher Associations in Russia: Formation of Middle Leaders
}

\author{
Anatoly V. Merenkov \\ Ural Federal University
}

Correspondence regarding this article should be addressed to Anatoly V. Merenkov, Department of Applied Sociology, Ural Federal University, 19 Mira str., Ekaterinburg, Russian Federation, 620002. E-mail: anatoly.mer@gmail.com

\author{
Natalya L. Antonova \\ Ural Federal University
}

\begin{abstract}
Correspondence regarding this article should be addressed to Natalya L. Antonova, Department of Applied Sociology, Ural Federal University, 19 Mira str., Ekaterinburg, Russian Federation, 620002. E-mail: n-tata@mail.ru
\end{abstract}

\author{
Natalia G. Popova \\ Ural Branch of the Russian Academy of Sciences
}

\begin{abstract}
Correspondence regarding this article should be addressed to Natalia G. Popova, Sector of Theoretical Linguistics and Academic Communications, Department of Foreign Languages, Institute of Philosophy and Law, Ural Branch of the Russian Academy of Sciences, 16 Sofia Kovalevskaya str., Ekaterinburg, Russian Federation, 620099. E-mail: ngpopova@list.ru
\end{abstract}

\begin{abstract}
This research study is aimed at investigating distributed leadership practices in the Russian school system, of which professional teacher associations (PTA) constitute a distinct feature. In particular, we set out to investigate the PTA leadership potential, as well as the role and specific personal characteristics of middle leaders in the Russian school education system. These associations are formed by the school administration on the basis of subject areas, bringing together teachers of maths, history, etc. Teachers join PTAs on a voluntarily basis. The key function of such organisations consists in the implementation of innovative educational approaches and techniques. In order to analyse their leadership potential, we carried out a sociological survey among the employees of high-profile secondary schools (gymnasiums and lyceums) situated in the major Russian city of Ekaterinburg. The research methodology comprised structured interviews with 110 respondents, along with in-depth interviews with 2 school directors, 4 school deputy directors and 6 heads of professional teacher associations. Our results show that the fundamentals and principles of distributed leadership are actively implemented in Ekaterinburg schools. The school administrations encourage the creation of professional teacher associations grouped around subject areas, delegating to these structural units the functions of improving the quality of teaching the respective subjects and disseminating educational innovations, at the same time as fulfilling the requirements of the state and regional education authorities. Such associations are headed by middle leaders, who are nominated by their colleagues and whose candidacy is approved by school seniors, taking into account their professional achievements, experience of leading pedagogical innovations and the presence of the right personal qualities necessary for productive collaborative work. These people perform the role of mediators, operating at the interface between various levels within the school. Although viewed as a school's personnel reserve for the positions of principals and head teachers, our respondents consider themselves to be 'more teachers' or 'innovators in education' than administrators. The development of the leadership qualities of such professionals in the Russian school system is shown to be hindered by a 'glass ceiling' - a certain limit in their career growth. This discouraging factor results in some middle school leaders searching for professional self-realization opportunities outside the school system, in the spheres of business, science or culture that are believed to provide more opportunities for self-advancement.
\end{abstract}

Keywords: leadership; distributed leadership; middle leadership; school; professional teacher associations; teacher leaders; teachers 


\section{Introduction}

Today, at a time when school education is experiencing another developmental wave (Townsend 2009), various theoretical and practical aspects of school leadership are attracting much research attention globally (to name a few, Bogotch \& Townsend, 2008; Leithwood. 1992; Elmore, 2000; Sun et al., 2017; Parmenter, 2012; Khudriyah, 2017). The accumulated empirical data and developed models have shown that effective leaders indirectly, but powerfully affect both school effectiveness and student achievement. Such leaders generate innovative approaches to education and encourage the self-development of their colleagues. However, the individualcentred notion of leadership is fading, increasingly giving way to a 'post-heroic' view (Gronn, 2002; Conger \& Pearse, 2003) on leadership as a distributed phenomenon (Harris, 2003; Harris, 2010; Crawford, 2012).

Distributed leadership is a collective form, implying multiple sources of guidance and direction amalgamated by a common culture, when teachers become experts ready to be involved in school improvement processes. This form is considered to be advantageous both to school and teacher development (Avolio, 2003; Harris, 2009; Hallinger \& Heck, 2010), primarily because it creates favourable conditions for the organisational commitment of teachers, which is known to be strongly related to their effectiveness (Park, 2005; Hulpia \& Davos, 2010). It should be mentioned that distributed leadership is seen as an organisational resource, serving school improvement; the core of the process is formed not only by successful school principals, who create conditions for translating innovative ideas into practice (Haiyan et al., 2016; Ganon-Shilon \& Schechter, 2018), but also middle leaders - teachers to whom leadership is distributed. In other words, middle leadership can be seen as a manifestation of distributed leadership and should be analysed through its theoretical lenses (Larusdottir \& O’Connor, 2017).

Researchers have investigated various aspects of middle leadership in school education. Theoretical research sets out to draw a distinction between overlapping concepts and create a suitably comprehensive model, while more practically-oriented studies are aimed at scrutinising tasks, relationships, motives and organisational scenarios behind real leadership practices (see e.g. Bullock et al., 1988; Wise, 2001; Earley \& Bubb, 2004; Bennet et al., 2003). Many of these investigations have revealed, along with the highly positive effects of fostering middle leadership, some potentially negative consequences, such as the incompatibility of roles (administrator and teacher) that middle leaders perform, or their reluctance to supervise and assess the work of their colleagues. Therefore, in order for middle school leadership to fulfil its transformative mission while avoiding the pitfall of becoming another practically unrealizable construct, more empirical evidence is needed. Moreover, the analysis of middle leadership practices in various sociocultural contexts can be a valuable contribution.

In this paper, we set out to investigate the PTA leadership potential, as well as the role and specific personal characteristics of middle leaders in the Russian school education system, which has some unique - and presumably interesting for today's professionals - experience of providing high-quality education (Minina, 2016).

\section{Sociocultural context}

In contemporary Russia, the problems of school reform are widely discussed; however, relatively little attention is paid to issues associated with leadership. Thus, a simple search across the Russian Citation Index database using the tag "school leadership" gives very few hits. We consider this to be a serious shortcoming, since the Russian school system is currently experiencing a radical transformation period as a result of both globalising factors and processes following the demise of the previous political system. Teachers who are capable of innovation and who passionately work to transform the educational process can become the drivers of necessary change (Leithwood et al,. 2006; Hall et al., 2012; Teleshaliyev et al., 2019).

In the Russian school system, a search for new, more effective educational approaches is traditionally carried out within so-called "methodical associations" (Rus. metodicheskye obedinenia) - hereafter referred to as professional teacher associations (PTAs) that are formed by the school administration around a subject area, e.g. a "PTA of math teachers" and joined by teachers voluntarily ${ }^{1}$. Such associations began to emerge in the late 19th century

\footnotetext{
1 The formation and activity of PTAs is regulated by article 19 in the RF Ministry Education Act http://www.consultant.ru/document/ cons_doc_LAW_140174/0358c09729e9c3b2eb0d551733d014138730196f/
} 
with the primary mission of exchanging experience between teachers working in the same subject area, which was believed to bolster the overall quality of students' education. A PTA member was encouraged to actively collaborate with colleagues in order to create conditions for all schoolchildren to enjoy equal opportunities of successful development. Municipal government bodies would encourage the creation of PTAs at the level of districts or the whole city with the idea of experience transfer between different schools.

Today, in terms of organisation, the Russian school system involves the following levels. A school director and his/her deputies for educational and upbringing ${ }^{2}$ work occupy the highest ranks in the administrative hierarchy. In cases where a school is attended by 700-1000 children, when students of primary, secondary and high schools study together, a deputy director is allocated for each school level. Directors and deputy directors are endowed with administrative functions, including organisation, planning and control of teachers' work in compliance with the requirements of the RF Ministry of Education and other regional and municipal education authorities. At the middle level, the work of teachers is supported by special institutional organisations, PTAs, created to solve complicated educational matters taking into account the specifics of the disciplines they teach. Schools form PTAs when there are several teachers (minimum 3) who teach a certain subject, e.g. history, physics or biology. An average Russian school operates 7-10 PTAs. In primary schools, due to the specifics of working with 7-10-year-old children (implying not only the knowledge component, but also a particular upbringing approach), PTAs unite all primary school teachers irrespective of their subjects. A PTA head is not expected to perform any administrative functions; rather, he/she is mainly responsible for organizing the work of teachersPTA members in such a way so as to create favourable conditions for students to build a positive attitude to learning and improve their academic performance.

Ten years ago, Russia experienced a major shift in educational policy, with its reform package being similar to the global policy agenda and including raised academic performance standards, standardised quality control and assessment, reduced state budget expenses and increased international competitiveness. Russia's Ministry of Education launched a series of reform initiatives, the most significant of which consisted in implementing new State Educational Standards. According to these documents, Russia's educational ideology, which was previously rooted in centralisation, collectivism and conformity, was now to be informed by new educational neoliberal values of "regional differentiation, student-centred learning, standardisation, institutional accountability, educational equity and quality assurance" (Minina 2016). Taking into account functions delegated to PTAs in the Russian education system, it can be supposed that it is these associations that become the agents of such a radical change. Now they face the challenge of searching for innovative approaches in education and upbringing that would allow a student to develop "third millennium" skills (Townsend, 2009).

In their work, PTAs implement activities of various formats, such as the collective discussion of scientific methodological professional literature (disputes, forums, etc.); presentations by PTA members devoted to various relevant issues; analysis of particular difficult pedagogical cases; lectures by invited specialists on the psychology of various ages and children's behaviour; collaborative practical work of teachers aimed at developing teaching materials, illustrative materials and tests; etc. (Andrunik \& Vasenina, 2015). In addition, PTAs play an important role in facilitating social and professional adaptation of young teachers by providing support and expertise (Chernikova, 2008).

Moreover, PTAs bear the responsibility for teachers' development, for making them more flexible, adaptable and professional. Not the least important of these is the role of PTAs in relieving tensions that inevitably arise between the parties to the educational reform process. It should be borne in mind that the work of such associations is inspired by middle leaders, who are elected to this position by their colleagues due to their high achievements in educating children.

\section{Theoretical considerations}

When people engage in any kind of joint activity, they inevitably reveal different levels of eagerness, enthusiasm and readiness to contribute to common goals. Following the social process of intragroup role differentiation, the group distinguishes between those who are proactive in formulating common work aims, prompt in performing

2 Upbringing (vospitanie) - In post-Soviet contexts, there is a distinction made between educational and upbringing processes and outcomes, with teachers often expected to take on responsibility for the latter, while in Western contexts upbringing is generally thought to be the sole responsibility of parents and guardians 
their tasks and setting quality standards, and those who tend to maintain discussions already initiated by active group participants. Such a distribution of roles and functions between individuals engaged in any social group is known to be determined by several factors, which will be discussed below.

It should be noted that people inherently differ in terms of their readiness to engage in particular kinds of work (Balthazard et al., 2012; Arvey et al., 2006). Thus, the propensity to master a particular profession is determined first of all by a person's natural talents. If someone has received an education that allows their natural talents to be fully realised, they are more likely to perform better in this profession compared to others. Secondly, people differ in their "psychological activity" (Vygotsky, 1978) when completing various kinds of work: some are quick and effective, while others achieve their goals by taking a more plodding approach. Thirdly, it is a person's individual characteristics that determine his/her willingness to propose and carry forward his/her own plan for realising the group's goals. This trait frequently points towards this person having the ability to become a successful leader provided the necessary conditions are present.

When seeking approaches to identifying new leaders, practitioners frequently turn to the theory of distributed leadership (Bolden, 2011), which has been extensively used in schools during implementation of new programmes aimed at increasing the quality of education. Educational institutions today are characterised by a complex structure, which cannot be managed by a single person. Distributed leadership implies that various functions and tasks are performed by people having respective skills and personal resources (Schermerhorn, Osborn, UhlBien \& Hunt, 2012). Göksoy (2015), in his study on the problem of leadership in educational institutions, showed that the theory of distributed leadership does facilitate a more efficient allocation of responsibilities among a large number of employees. Such an approach, while recognising the role of the principal, shows that leadership becomes collective rather than individual practice (Spillane, 2006). The distributed leadership in school can only be implemented provided careful planning, flexibility and (importantly) the absence of workplace coercion (Collins \& Hansen, 2011; Hogg, 2011). In order to form a solid foundation for distributed leadership, professional collaboration between teachers should be focused and disciplined (Jones \& Harris, 2013). This encourages a 'collective effectiveness', which allows higher educational results to be achieved (Hargreaves, Boyle \& Harris, 2014).

Along with the theory of distributed leadership in school, much attention has been recently drawn to the concept of middle leadership. This is largely because the implementation of distributed leadership has certain practical limitations. Thus, Harris identified barriers to innovations in schools due to teachers' inability to realise their creative potential (Harris, 2009). Middle leadership focuses on revealing teachers potentially capable of becoming leaders (middle leaders). Compared to distributed leadership, this is a bottom-up process, which is seen as a promising driving force in improving the quality of education (Fleming \& Amesbury, 2012; Seong \& Ho, 2012; Heng \& Marsh, 2009; Fletcher-Campbell, 2003; Hammersley-Fletcher \& Strain, 2011)

A possible practical solution is the creation of a two-tier system of identifying potential leaders in educational institutions. At the first stage, the school principal singles out those employees, who not only have had a positive experience of innovations, but also demonstrate leadership personal qualities. These people become heads of teacher associations engaged with a search for optimal educational methods in their subject fields. At the second stage, a collaborative work within such small teams reveals individuals that show higher, compared to others, professional results. In other words, a specific kind - initiative leadership - appears, when a teacher becomes a leading subject in the improvement of the professional activity of his/her colleagues. In this paper, we will attempt to show how such a system, with its advantages and limitations, is realised in Russian schools.

The process of formation of leadership qualities implies the influence of both internal and external factors. Any group is characterised by an 'inherent' need for people capable of initiating collective action leading to the accomplishment of common goals by forming their mental representation, distributing responsibilities among the group's members, managing the process of their realisation, etc. This factor is considered to be essential in revealing latent leadership qualities in group participants. In cases where several group members possess such potential, there emerges the possibility of competition for the position of leader. Contemporary theory also emphasises the specifics of the leader's orientation - whether leaders are primarily motivated to achieve public good or derive personal benefits (Maner \& Mead, 2010).

Leaders are expected to take verbal and practical actions to persuade other group members that proposed plans 
are feasible and will produce the desired results. We believe that among all kinds of persuasion, there are two that an effective leader should master - setting their own example of successful achievements and inspiring others to follow it using all possible means. Hence, the leader should not only demonstrate talents higher than the average level of the group with respect to the work being engaged in, but also the ability to organise and coordinate collective action. Knowledge and skills that underpin such leadership capacity can be formed either by taking leadership courses or gaining practical experience of managing other people. Without these qualities high professionalism and leadership capacity - a person is highly unlikely to be recognised as leader by the other group members. However, it should be emphasised that professional supremacy alone cannot be a sufficient condition for a person to become a leader: it is essential that other people be ready to reproduce his/her example in their work and behaviour. In such a way, the unique culture of a group is nurtured and transmitted to new group members, creating conditions for the successful realisation of the group's goals. A person remains leader for as long as his/her individuality continues to secure high group achievements.

\section{Materials and Methods}

\section{Research design}

In order to investigate the PTA leadership potential, as well as the role and specific personal characteristics of middle leaders in the Russian school education system, in 2017-18, we carried out a sociological survey among the teaching and administrative staff of a number of lyceums and gymnasiums situated in a major Russian city of Ekaterinburg.

We singled out the following research questions: 1) to understand why school teachers in Russia today make the decision to participate in a PTA; 2) to elucidate a set of tasks that PTAs aim to solve; 3) to reveal qualities required for a school teacher to become a PTA leader; 4) to investigate positive experience of successful PTA heads.

In this study, we applied mixed research methodology, following the idea of the importance of an optimal balance between quantitative and qualitative sociological instruments (Creswell, 2009). This approach allowed us to answer the formulated research questions, thus giving an improved understanding of the specifics of functioning of PTAs in the system of Russian school education. The basis for the study was the QUAL-quan strategy (Morgan, 2014), which implies the dominant role of qualitative instruments. Quantitative research was used for generalisation of qualitative data and identification of main trends.

\section{Participants}

In-depth interviews were carried out with 2 school directors, 4 deputy-directors and 6 PTA heads. The teaching experience of each school director and deputy-director was over 20 years. Among 6 PTA heads, 2 and 4 had the teaching experience of $10-20$ and over 20 years, respectively.

Standardised interviews were conducted with 110 teachers working with schoolchildren of various levels (from $1^{\text {st }}$ to $10^{\text {th }}$ form). The gender distribution among the respondents was as follows: $15 \%$ men and $85 \%$ women. The respondents' age varied from 25 to 70 years. The respondents were also distributed with regard to their professional experience: $64 \%$ had worked in the school system for over 10 years, with $13 \%, 15 \%$ and $8 \%$ having a teaching experience of $6-10,2-5$ and less than 2 years, respectively. Therefore, our sample was primarily composed of professionals having an extensive intellectual capability that can be applied in continuous professional development.

In terms of subject area, our respondents represented all major kinds of PTAs operating in Russian schools: 15\% - English language, $14 \%$ - maths, $12 \%$ - science, $11 \%$ - Russian language and literature, $10 \%$ - primary school, $9.5 \%$ - information technology, $9 \%$ - history and social sciences, $8 \%$ - physical education teachers. The rest of the sample were small-sized PTAs, whose members were involved in teaching the second foreign language or history of world arts. A typical PTA included from 4 to 10 teachers. 


\section{Instruments}

Qualitative study. An in-depth interview guide with school and PTA heads was developed. It included 13 open questions implying a detailed answer, which allowed the respondents to express their opinion independently. The interviews were carried during the respondents' free time in the form of face-to-face meetings in the schools where they worked. The average interview time was 45 minutes. The interview results were decoded, with the respondents' answers to the same questions being grouped together. Such a grouping allowed identification of typical and specific features in the answers, thus facilitating interpretation of the results.

Quantitative study. A standardised interview guide that included 15 questions was developed. This guide was initially tested over the course of a pilot study among 20 teachers. After the pilot study, two guide questions were re-formulated to make them more comprehensible to the respondents. The teachers were questioned in their free time in the schools were they worked. The average time spent on filling in the questionnaire was 20 minutes. The results were processed using specialized software for sociological and marketing information Vortex 10.

\section{Results and discussion}

Our research has revealed the main factors behind the respondents' motivational structure to become a PTA member. For $69 \%$ of the respondents, the key motive was the permanent possibility to exchange experience with colleagues teaching a similar subject (hereafter, percent shows the results of quantitative study). According to $64 \%$ of the respondents, PTAs allow the professional teacher community to solve acute common problems associated with the need to improve the quality of children's education. Some teachers, however, mentioned an administrative factor: $41 \%$ of the respondents believe that teachers should be part of a least one PTA. The latter respondents supported the idea that teachers should have the freedom to move between various PTAs. According to one respondent (social sciences PTA head, teaching experience 12 years): "When our association of social science teachers was joined by a literature teacher, it significantly boosted our work. He showed how a student's interest in learning about human nature can be raised using the arts. This inter-subject collaboration has diversified the methods of our teaching" (hereafter, quotes are given either from open questions included in the questionnaire or from in-depth interviews).

Around $38 \%$ of the respondents pointed out that the collaboration within a PTA is frequently a factor encouraging them to implement new teaching strategies and develop new forms of lessons. New ideas arise when teachers attend each other's lessons and subsequently discuss their quality and productivity. "As a PTA, we aim to test various methods of classroom organisation that create an environment conducive for learning. While attending each other's lessons, we focus on individual teaching techniques that may be shared among the PTA members. As a PTA head, I also check whether the methods and techniques used by teachers are in compliance with state educational standards" (natural science PTA head, teaching experience 38 years). Our results show that PTAs hold regular meetings, no less than once a month, with the topical discussion point (mentioned by $9 \%$ of the respondents) being the introduction of educational innovations in the teaching and upbringing of children both at school lessons and during extra-curriculum activities.

Our research has revealed a certain controversy between the education directions set by Russia's state education documents $^{3}$ (Russia's Federal Standard for Secondary Education 2014) and orientations pursued by our respondents. According to the state documents, education should be primarily aimed at creating favourable conditions for a child to develop such moral qualities as patriotism, respect for Russia's multi-ethnicity, acceptance of traditional social values, motivation for creativity and innovation, fundamentals of lifelong selflearning, propensity for collective work, responsibility for one's family, society and humankind. Conversely, the majority of our respondents are shown to be preoccupied with the development of teaching methods. Only $17 \%$ of the respondents, largely primary school teachers, asserted that the main motivation behind their participation in a PTA consists in an opportunity to improve their upbringing approaches: "Bringing up a child is a difficult task. Every teacher has his/her own techniques for maintaining discipline in the classroom and productive collaboration with parents. Unfortunately, there is no single upbringing method applicable to all children. When you teach chemistry or physics, you make children comprehend and memorise the material,

\footnotetext{
${ }^{3}$ Russia's Federal Standard for Secondary Education http://mosmetod.ru/metodicheskoe-prostranstvo/uchebnaya-literatura/normativnyedokumenty/prikaz-minobrnauki-rossii-ot-6-oktyabrya-2009-g-413.html (accessed 05/04/18)
} 
whereas upbringing implies forming a child's aptitude to follow rules. If there had been reliable pedagogical approaches for achieving this, we would have created a PTA specialising in moral education long before" (gymnasium deputy-director, work experience 22 years).

Table 1 presents aims and objectives that PTAs are expected to achieve (according to the respondents).

Table 1

Aims and objectives set by PTAs (\% of number of respondents)

\begin{tabular}{llc}
\hline No. & \multicolumn{1}{c}{ Aims and objectives } & \% \\
\hline 1 & Increasing the quality of subject teaching & 74 \\
2 & Implementation of innovations developed by PTA members & 57 \\
3 & Discussions around problems of responding to new normative state documents & 56 \\
4 & Analysis of new education and pedagogical techniques developed by PTA members & 43 \\
5 & Consolidation of PTA members' efforts, coordination of their work & 31 \\
6 & Exchange of professional experience between PTA members and various PTAs & 25 \\
7 & Collaborative efforts in preparing children for participation in various subject competitions, olympiads and & 22 \\
& contests & 19 \\
9 & Support for proactive teachers & 14 \\
\hline
\end{tabular}

Thus, quality is viewed as the major education aim; this agrees with many studies (Daring-Hummond, 2000; Barrett et al., 2006) showing that quality of teaching is a major influence on student achievement. According to a respondent (literature and arts PTA head, teaching experience 10 years): "Our PTA sets many aims and objectives, but the quality of education is certainly the top priority. We want our children to pass the Unified State Exam (Yediniy gosudarstvenniy ekzamen, EGE - a series of exams every Russian student passes after graduation from school) and achieve higher results than children in other schools in the city. This is how our professional achievements are judged". As an aside, the results of this study show that, although Russia's new educational agenda asserts a radical break from Soviet era pedagogy in establishing a new system of quality assurance (instead of quality control), in practice, Russian educators still treat education quality almost exclusively as an outcome, rather than a process-oriented phenomenon. These findings are in agreement with a critical study of E. Minina, who showed that "the 'quality revolution' in Russian education has been skin-deep and largely confined to the realm of rhetoric" (Minina, 2006, p.16).

The dissemination of innovations that individual teachers introduce in their practice is regarded as a means of increasing the overall quality of education (Serdyukov, 2017). PTA heads see it as their mission to involve the majority of the teacher community in the process of innovation creation. Technically, this is performed through attending each other's lessons with subsequent analysis of particular educational and pedagogical techniques: "During the analysis of our colleague's lesson, we give him/her feedback by providing practical recommendations with regard to what can be improved. Our task is to allow every PTA member to prove themselves, because every teacher is talented in their own way. There is always something to learn from each other. As a PTA head, I attempt to select those topics for discussion that can enrich other members professionally" (maths and science PTA head, teaching experience 28 years). Such discussions, initiated by PTA heads as middle leaders, help teachers to stand together and understand that their creative ideas are valued and required - this contributes to the effective work of all teachers.

PTA heads are shown to encourage teachers to raise their professional competency not only through participation in a single PTA, but also by gaining experience outside their workplace. The organisation of such learning possibilities is another function of school middle leaders. About $64 \%$ of the respondents mentioned a positive effect of experience exchange with teachers working in other schools and $50 \%$ - from attending lessons of other subject teachers. Moreover, $47 \%$ - and $31 \%$ - of the respondents believe that their professional growth is impossible without acquiring a knowledge of the best educational practices of leading Russian - and world teachers, respectively. "A physics teacher told us that self-evaluation lists are successfully applied in China. I started implementing this approach in my $5^{\text {th }}$ form class and found that the children evaluated themselves much more strictly than teachers would. Children found this work highly encouraging because they felt trusted. Our teachers went further and started asking their students to assess each other's assignments. In doing so, 
children learn to take into account their peers' individual characteristics" (natural sciences PTA head, teaching experience 38 years).

Our findings demonstrate that Russian school middle leaders are eager to broaden the horizons of domestic educational practice by using the experience and innovative approaches developed abroad. An advantage of the Internet era is the provision of a global space for pedagogical innovation transfer (Vieluf et al,. 2012), which allows proactive teachers to constantly improve their professional level. PTA heads are shown to play the key role in this process: they are continually searching for information about professional developmental events, e.g. conferences, webinars or learning courses. "Every year we send the members of our PTA to professional conferences in other Russian cities, to Moscow and St. Petersburg universities, because they have already made the most of the Regional Centre for Education Development. On the other hand, teachers from other Russian regions come to our school to attend lessons and participate in discussions organised by local PTAs" (gymnasium director, work experience 45 years).

Every third respondent mentioned that PTAs are important because their work allows teachers to boost their personal commitment to the profession; in particular, a teacher's desire to provide a child with the broadest education possible. The importance of personal commitment was also emphasised by (Muijis \& Reinolds, 2001; Park, 2005; Razak et al., 2009). As Park (2005) pointed out, dedicated and highly committed teachers demonstrate a greater responsibility and accountability in work, thus becoming a major factor in quality education.

It is interesting that PTAs in Russian schools are not merely volunteering organisations. Their work can be simultaneously seen as a bottom-up and top-down initiative. On the one hand, PTAs are school structural units, the work of which is controlled by school administrations (as was mentioned above, a PTA head candidacy has to be approved by senior school leaders); on the other, PTAs are based on democratic principles in that they are free to nominate their leaders, apply stimulating or coercive measures to the members, insist on the implementation of certain educational methods, etc. The work of a PTA head is paid according to school tariffs, which become an external motivation to participate and grow within a PTA for all its members. The work of most active participants and significant professional achievements are supported financially (typically by an annual bonus), the decision of which is taken during PTA meetings by general voting. Therefore, the productivity of PTA work is dependent on whether an optimal balance between pressure from above and bottom-up initiatives has been achieved. When the former factor is stronger, then the PTA can become another administrative burden imposed on a teacher and devoid of any inherent meaning and potential. Conversely, too much freedom can result in decreased teaching quality. It seems likely that it is the personality of the PTA head that influences to which side this 'pendulum' will swing.

Let us consider this factor (the leadership qualities of middle leaders), determining the efficiency of PTAs as agents of educational change, in greater detail. About $50 \%$ - and $34 \%$ - of our respondents believe that the majority - and almost all - teachers participating in the work of PTAs, respectively, are potentially capable of innovative work. This shows that the professional level of the majority of PTA members allows them to become leaders in their work. However, as was mentioned earlier, their professional competency should be accompanied by specific human qualities necessary for the position of leader. Table 2 summarises our respondents' answers with regard to such leadership characteristics.

Among various leadership qualities, our respondents gave top priority to the ability and eagerness to master new things and develop (on their basis) more effective pedagogical approaches that can be further tailored to suit the needs of a particular child. "All children are different, but teachers are expected be able to educate everyone. We keep on searching for new methods as there are no universal solutions. Teachers need to be way ahead of the time and apply the following principle: the older you become, the faster you should run to catch up with the times. There are, however, teachers that are reluctant to learn - I believe they should be dismissed" (gymnasium deputy-director, work experience 37 years). Another distinct leadership quality mentioned by over half of our respondents is the desire for self-realisation, which is believed to be measured by high student achievements. "Our most successful PTA members have students who have won regional and all-country olympiads" (French language PTA head, teaching experience 23 years). When asked how many of their PTA colleagues have leadership capacity, 59\% saw this potential in the majority of the PTA members, while $26 \%$ believed that only a minority of teachers have the necessary qualities for this position.

Our respondents' opinions regarding how leadership qualities are manifested are summarised in Table 3. 
Table 2

Personal qualities characterising the middle leader (\% of number of respondents)

\begin{tabular}{llc}
\hline No. & \multicolumn{1}{c}{ Personal quality } & $\%$ \\
\hline 1 & Ability to create and master new things & 81 \\
2 & Proactivity & 70 \\
3 & Desire to facilitate the realisation of children's natural talents & 68 \\
4 & Desire for self-realisation and professional growth & 58 \\
5 & Respect for tradition and accumulated cultural experience & 43 \\
6 & Desire to reveal one's own managerial qualities & 4 \\
7 & Desire to gain recognition among colleagues & 3 \\
\hline
\end{tabular}

Table 3

Manifestations of leadership qualities within a PTA (\% of number of respondents)

\begin{tabular}{lll}
\hline No. & & \multicolumn{1}{c}{ Manifestations } \\
\hline 1 & Continuous preparation of students for participation in subject competitions and olympiads & 77 \\
2 & Active participation in regular PTA meetings & 51 \\
3 & Active participation in the implementation of PTA decisions & 41 \\
4 & Presentations of new innovations to colleagues & 37 \\
5 & Presentations of own educational developments to colleagues & 31 \\
6 & Assistance to colleagues in mastering new approaches and skills & 26 \\
7 & Active participation in the realisation of state requirements & 11 \\
8 & Active participation in the analysis of educational methods and techniques developed by other PTA members & 5 \\
\hline
\end{tabular}

Since student achievements are considered to be the main factor encouraging teachers to undertake innovative behaviour, it is no wonder that this criterion is applied to assess leadership potential. Our results show that those teachers whose students demonstrate high educational achievements, e.g. in subject competitions and olympiads, are perceived as leaders. The more students a teacher has prepared for such events, the higher authority he/she enjoys among colleagues. A teacher in possession of such professional attributes is considered to have the right to put forward suggestions aimed at increasing the professional competencies of his/her colleagues.

The ability to teach not only children, but also adults allows PTA leaders to secure their leadership positions. This is manifested in the assistance provided to other PTA members in tailoring new educational and pedagogical methods to the needs of particular students. According to $51 \%$ of our respondents, PTAs consisting of 7-8 members have only 2-3 people with distinct leadership qualities, while $14 \%$ believe that PTAs of such a size have only 1-2 potential leaders. Paradoxically, $25 \%$ of the respondents working in smaller-sized PTAs (4-6 teachers) stated that all PTA members manifest leadership characteristics.

Our research has revealed the significance of various professional achievements that allow a PTA member to assert a claim to leadership positions within the group, the ranking of which are given in Table 4 .

Table 4

Professional achievements necessary to be recognised as leader (\% of number of respondents)

\begin{tabular}{lll}
\hline No. & Professional achievements & \% \\
\hline 1 & High student achievements in the subject & 83 \\
2 & High student achievements in subject competitions and olympiads & 78 \\
3 & Own victories in professional competitions & 44 \\
4 & Innovative educational techniques recognised by colleagues & 43 \\
5 & Participation in teacher conferences & 39 \\
6 & Scientific publications & 30 \\
7 & Significant results in terms of upbringing & 16 \\
\hline
\end{tabular}


At a certain moment, when a teacher has accumulated a sufficient amount of professional achievements, his/her colleagues or the school administration may propose his/her candidacy to the position of PTA head. According to our respondents, this becomes a significant point in a teacher's career. "Teachers that have an ambition to become a PTA head should have an extensive record of achievements. Mine are gathered in two thick folders, containing documents with the records of my students' achievements and confirmations of regular professional training in various pedagogical directions. The latter include not only training programmes in my subject area, but in teaching gifted children, organisation of project work, certificates of honour for extracurricular work, participation in teacher conferences, etc. Although we never compare our achievements, they are important both for the teacher's career and for the PTA's standing among other PTAs, because we compete with colleagues in other schools" (foreign language PTA head, teaching experience 27 years).

As our research shows, some leaders stand out in a group due to their particular results in a single field, e.g. demonstrating better publication rates. As a rule, such a teacher, though being a PTA member, orients him/ herself towards the dissemination of positive experiences among all teachers in the school, because these achievements are relevant to the work of the school as a whole. "We have a young teacher who is very active in using IT in her teaching practice. She shows promise as a leader through distributing her experience among all teachers" (gymnasium deputy-director, work experience 32 years).

However, it seems that today's leaders are driven by the desire for personal self-realisation rather than for the development of a pedagogical community or educational organisation. "There are teachers who burn the candle at both ends at work, but they are always a tiny minority. I have noticed that these people little by little stop being a team member; rather, they are leader-loners, working only for themselves and looking for some other opportunities outside the school" (gymnasium deputy-director, work experience 38 years). According to one school director, our respondent, the reason may be restricted possibilities for professional growth within the school education system. "The maximal approval that many teachers receive for their work are the certificates of honour issued by district, city, region or Ministry of Education authorities" (gymnasium deputy-director, work experience 38 years).

Our study has revealed the problem of limited perspectives for professional growth that Russian middle school leaders currently experience. In most cases, the maximal professional level that middle leaders can reach is the position of a PTA head. Although this position is supported financially, no other stimulating mechanisms are applied by school administrations in order that middle leadership might become a reason for teachers to stay and progress within the school system. As a result, driven by the desire for self-realisation inherent to people with natural leadership qualities, school middle leaders begin looking for opportunities outside the school system - in business, science or culture. According to our respondent: "Many school middle leaders do not strive to become a district PTA head largely because this work, while being incredibly physically, mentally and emotionally resource demanding, gives very little professional satisfaction. These positions are not seen as a major career progression" (gymnasium deputy-director, work experience 21 years). Moreover, all official positions in the Russian system of education and science imply a significant burden of bureaucratic chores (reports, etc.) and tendency to conformity (Popova et. al, 2017), which also become an additional discouraging factor for middle leaders. "I was put forward to become a head teacher (zavuch) in my previous school, but I did not agree. I like working with children and hate writing loads of unnecessary papers. My students have won first prizes in all-Russia competitions - this is much more important to me" (Russian language and literature PTA head, work experience 25 years).

About $20 \%$ believe that middle school leaders cannot progress further than the position of PTA head, because PTA heads rarely become head teachers, school directors or education management department heads. "We frequently see that a person was appointed to the positon of school director without any apparent professional achievements. It seems that the main selection criterion is a person's ability to interact with authorities and conform to the requirements of top education managers" (maths PTA head, work experience 37 years).

Our findings show that the creation of a focused state policy for encouraging and supporting middle leadership in Russian schools is critical; otherwise, such a valuable resource for the future development of the school system as PTAs can be wasted. Further research is needed to reveal the specifics of this phenomenon and elucidate all the obstacles for the formation of efficient middle leaders within the school system. 


\section{Conclusion}

In the course of our study, we have examined the leadership potential of professional teacher associations (PTAs) operating in the Russian school system. The research findings can be broadly summarised into the following focal points.

1. The fundamentals and principles of both distributed and middle leadership are actively realised in Ekaterinburg schools. School administrations initiate the creation of PTAs grouped around subject areas and delegate to these structural units the functions of improving the quality of teaching the respective subjects and disseminating educational innovations, at the same time as fulfilling the requirements of the state and regional education authorities.

2. Every PTA is headed by a teacher who is put forward to this position by the PTA members, and whose candidacy is approved by the school administration. The middle leader is selected on the basis of both his/her high professional results (student subject and extracurricular achievements, such as prizes in competitions and olympiads) and personal leadership qualities (initiative, organisation and ability to create and master new things). Such a combination of professional achievements and personal qualities commands trust and respect from his/her colleagues, encouraging them to follow the leader in implementing educational innovations.

3. Middle leaders should be viewed as a school's personnel reserve for the positions of senior leaders, i.e. directors and head teachers. However, in today's Russia, middle leaders are rarely appointed to these positions due to a poorly organised career progression mechanism. In addition, middle leaders, operating at the interface between various levels within the school, consider themselves to be 'more teachers' than administrators.

4. The activity of teachers participating in PTAs is determined by their orientation towards innovation and professional assertiveness - potentially leadership qualities. The formation of middle leaders is, however, hindered by existing boundaries within the school system, limiting their career progression. As a result, some teachers, who have the potential to become a middle leader and thus contribute to educational change, seek self-realisation outside the school system in such social spheres as business, science and culture that offer more opportunities for development.

In order for school middle leaders to carry out their potentially transformative role in contemporary education, both by maintaining traditions and keeping abreast of trends and innovations, a focused policy aimed at supporting everyday middle leadership practices is required. Otherwise, middle leadership in schools may remain merely an elegant concept, which in reality camouflages an increasing burden on teachers due to the delegation of responsibilities for completing tasks being passed down through the school hierarchy.

\section{References}

Andrunik, A.P., Vasenina, T.I. (2015). Professional teacher associations as a factor in the development of teachers' professional competencies. Vestnik Prikamskogo Sotsialnogo Instituta, 72(4), 3-13.

Arvey, R. D., Rotundo, M., Johnson, W., Zhang, Z., \& McGue, M. (2006). The determinants of leadership role occupancy: Genetic and personality factors. Leadership Quarterly, 17(1), 1-20. https://doi.org/10.1016/j. leaqua.2005.10.009

Avolio, B., Sivasubraminiam, N., Murry, W., Jung, D., \& Garger, J. (2003). Assessing shared leadership: Development and preliminary validation of a Team Multifactor Leadership Questionnaire. In C. L. Pearce \& J. A. Conger (Eds.), Shared leadership: Reframing the hows and whys of leadership (pp. 143-172). Thousand Oaks, USA: Sage.

Balthazard, P. A., Waldman, D. A., Thatcher, R. W., \& Hannah, S. T. (2012). Differentiating transformational and non-transformational leaders on the basis of neurological imaging. Leadership Quarterly, 23, 244-258. https://doi.org/10.1016/j.leaqua.2011.08.002

Barrett, A., Chawla-Duggan, R., Lowe, J., Nikel, J., \& Ukpo, E. (2006). Review of the 'international' literature on the concept of quality in education. Bristol, UK: EdQual.

Bennett, N., W. Newton, C. Wise, P. Woods, \& Economou, A. (2003). The role and purpose of middle leaders in schools. Nottingham, UK: NCSL.

Bogotch, I., \& Townsend, T. (2008). What are the essential leadership questions in a rapidly changing world? In 
T. Townsend \& I. Bogotch (Eds.), The elusive what and the problematic how: The essential leadership questions for school leaders and educational researchers (pp. 3-15). Rotterdam, Netherlands: Sense Publishers.

Bryman, A. (2007). Effective leadership in higher education: A literature review. Studies in Higher Education, 32(6), 693-710. https://doi.org/10.1080/03075070701685114

Bullock, A. (1988). Meeting teachers' management needs. Ely, UK: Peter Francis.

Conger, J. A., \& Pearce, C.L. (2003). A landscape of opportunities. In C. L. Pearce \& J. A. Conger (Eds.), Shared leadership. Reframing the hows and whys of leadership (pp. 285-303). Thousand Oaks, CA: Sage.

Chernikova,E.G.(2008). Factors in the social and professional adaptation of young teachers. VestnikCheliabinskogo Gosudarstvennogo Universiteta, 10(5), 171-179.

Collins, J., \& Hansen, M. (2011). Great by choice. Uncertainty, chaos and luck - Why some thrive despite them all. New York, NY: Harper Business Press.

Hogg, M. A. (2011). A social identity theory of leadership. Personality and Social Psychology Review, 5(3), 184-200. https://doi.org/10.1207/S15327957PSPR0503 1

Crawford, M. (2012). Solo and distributed leadership: Definitions and dilemmas. Educational Management, Administration and Leadership, 40(5), 610-620. https://doi.org/10.1177/1741143212451175

Creswell, J. (2009). Research design: Qualitative, quantitative and mix method approaches. Thousand Oaks, CA: Sage.

Darling-Hammond, L. (2000). Teacher quality and student achievement: A review of state policy evidence. Education Policy Analysis Archives, 8(1), 1-50. https://doi.org/10.14507/epaa.v8n1.2000

Earley, P., \& Bubb, S. (2004). Leading and managing continuing professional development. London, UK: Paul Chapman.

Elmore, R. (2000). Building a new structure for school leadership. Washington, D.C.: The Albert Shanker Institute.

Fleming, P., \& Amesbury, M (2012). The art of middle management: A guide to effective subject, year and team leadership. New York, NY: Routledge.

Fletcher-Campbell, F. (2003) Promotion to middle management: Some practitioners' perceptions. Educational Research 45(1), 1-15. https://doi.org/10.1080/0013188032000086082

Ganon-Shilon, S., \& Schechter, C. (2018). School principals' sense-making of their leadership role during reform implementation. International Journal of Leadership in Education, 22(3), 279-300. https://doi.org/10.1080/13 603124.2018.1450996

Gronn, P. (2000). Distributed properties: A new architecture for leadership. Educational Management and Administration, 28(3), 317-338. https://doi.org/10.1177/0263211X000283006

Gunter, H., D. Hall, \& Bragg, J. (2013). Distributed leadership: A study in knowledge production. Educational Management, Administration and Leadership, 41(5), 555-580. https://doi.org/10.1177/1741143213488586

Haiyan, Q., Walker, A., \& Xiaowei, Y. (2016). Building and leading a learning culture among teachers. A case study of a Shanghai primary school. Educational Management Administration \& Leadership, 45(1), 101-122. https://doi.org/10.1177/1741143215623785

Hall, D., H. Gunter, \& Bragg, J. (2012). Leadership, new public management and the re-modelling and regulation of teacher identities. International Journal of Leadership in Education, 16(2), 173-190. https://doi.org/10.108 $0 / 13603124.2012 .688875$

Hallinger, P., \& Heck, R.H. (2010). Leadership for learning: Does collaborative leadership make a difference in student learning?" Educational Management, Administration and Leadership, 38(6), 654-678. https://doi. org/10.1177/1741143210379060

Hammersley-Fletcher, L. \& Strain, M. (2011) Power, agency and middle leadership in English primary schools. British Educational Research Journal, 37(5), 871-884. https://doi.org/10.1080/01411926.2010.506944

Hargreaves, A., Boyle, A., \& Harris, A. (2014). Uplifting leadership: How organizaons, teams, and communies raise performance. New York, NY: Wiley.

Harris, A. (2003). Distributed leadership in schools: Leading or misleading. Management in Education, 16(5), 1013. https://doi.org/10.1177/089202060301600504

Harris, A. (2009). Distributed school leadership: Evidence, issues and future directions. Penrith, Australia: Australian Council for Educational Leaders.

Harris, A. (2010). Distributed leadership: Current evidence and future directions. In Bush, T., Bell, L. \& Middlewood, D. (Eds.), The principles of educational leadership and management. London, UK: Sage.

Heng, M. A., \& Marsh, C. J. (2009). Understanding middle leaders: a closer look at middle leadership in primary schools in Singapore. Educational Studies, 35(5), 525-536. https://doi.org/10.1080/03055690902883863

Hogg, M. A. (2011). A social identity theory of leadership. Personality and Social Psychology Review, 5(3), 184-200. https://doi.org/10.1207/S15327957PSPR0503_1

Hulpia, H., \& Devos, G. (2010). How distributed leadership can make a difference in teachers' organizational 
commitment? A qualitative study. Teaching and Teacher Education, 26, 565-575. https://doi.org/10.1016/j. tate.2009.08.006

Jones, M., \& Harris, A. (2013) Disciplined collaboration: Professional learning with impact. Professional Development Today, 15(4), 13-23

Khudriyah, K. (2017). The effect of leadership style and organizational culture toward teacher motivation of MTs Arrohman Jombang in academic of 2016/2017. Al-Idaroh: Jurnal Studi Manajemen Pendidikan Islam, 1(2), 1-17. Retrieved from http://jurnal.stituwjombang.ac.id/index.php/al-idaroh/article/view/16

Lárusdóttir, S. H., \& O’Connor, E. (2017). Distributed leadership and middle leadership practice in schools: A disconnect? Irish Educational Studies, 36(4), 423-438. https://doi.org/10.1080/03323315.2017.1333444

Leithwood, K., Day, C., Sammons, P., Harris, A., \& Hopkins, D. (2006). Seven strong claims about successful school leadership. Nottingham, UK: National College of School Leadership

Leithwood, K. A. (1992). The move toward transformational leadership. Educational, 49(5), 8-12.

Maner, J. K., \& Mead, N. L. (2010). The essential tension between leadership and power: When leaders sacrifice group goals for the sake of self-interest. Journal of Personality and Social Psychology, 99, 482-497. https://doi. org/10.1037/a0018559

Minina, E. (2016). Quality revolution' in post-Soviet education in Russia: From control to assurance? Journal of Education Policy, 32(2), 176-197. https://doi.org/10.1080/02680939.2016.1250165

Morgan, D. L. (2014). Integrating qualitative and quantitative methods: A pragmatic approach. Thousand Oaks, CA: Sage.

Muijs, D., \& Reynolds, D. (2001). Effective teaching: Evidence and practice. London, UK: Paul Chapman.

Ng Foo Seong, D., \& Ho, J. M. (2012). How leadership for ICT reform is distributed within a school. International Journal of Educational Management, 26(6), 529-549. https://doi.org/10.1108/09513541211251370

Razak N. A., Darmawan I. G. N., \& Keeves, J. P. (2009). Teacher commitment. In L. J. Saha \& A. G. Dworkin (Eds.), International handbook of research on teachers and teaching (vol. 21, pp. 343-360). Boston, MA: Springer.

Park, I. (2005). Teacher commitment and its effects on student achievement in American high schools. Educational Research and Evaluation, 11, 461-485. https://doi.org/10.1080/13803610500146269

Parmenter, L. (2012). Community and citizenship in post-disaster Japan: The roles of schools and students. Journal of Social Science Education, 11(3), 6-21.

Popova, N., Moiseenko, Ya., \& Beavitt, T. (2017). Conformity in modern science: An engine of societal transformation? Changing societies and personalities, 1(3), 237-258. https://doi.org/10.15826/cps.2017.1.3.017

Schermerhorn, J. R., Osborn, R. N., Uhl-Bien, M. \& Hunt, J. G. (2012). Organisational behaviour: Experience, grow, contribute. Hoboken, NJ: John Wiley and Sons Inc.

Serdyukov P. (2017). Innovation in education: What works, what doesn't, and what to do about it? Journal of Research in Innovative Teaching \& Learning, 10(1), 4-33. https://doi.org/10.1108/JRIT-10-2016-0007

Sun, J., Chen X., \& Zhang, S. (2017). A review of research evidence on the antecedents of transformational leadership. Education Sciences, 7(1),15. https://doi.org/10.3390/educsci7010015

Spillane, J. P., Halverson, R., \& Diamond, J. B. (2004). Towards a theory of leadership practice: A distributed perspective. Journal of Curriculum Studies, 36(1), 3-34.

Teleshaliyev, N., Vranjesevic, J., Celebicic, I., Joshevska, M., Miljevic, G. (2019). Non-positional teacher leadership in the post-socialist context. International Journal of Teacher Leadership, 10(1), 76-89.

Townsend, T. (2009). Third millennium leaders: Thinking and acting both locally and globally. Leader and Policy in Schools, 8, 355-379. http://dx.doi.org/10.1080/15700760802535278

Vieluf S., et al. (2012). Teaching practices and pedagogical innovation: Evidence from TALIS. Paris, France: OECD Publishing. https://doi.org/10.1787/9789264123540-e

Vygotsky, L. (1978). Mind in society: The development of higher psychological processes. Oxford, UK: Harvard U Press.

Wise, C. (2001). The monitoring role of the academic middle manager in secondary schools. Educational Management Administration \& Leadership, 29(3), 333-341. https://doi.org/10.1177/0263211X010293007 